This is the peer reviewed version of the following article:

Fabbri, M., Barbieri, P. N., Bigoni, M. (2019), Ride Your Luck! A Field Experiment on Lottery-Based Incentives for Compliance.

Management Science. DOI: 10.1287/mnsc.2018.3163

which has been published in final form at https://doi.org/10.1287/mnsc.2018.3163 .

This article may be used for non-commercial purposes in accordance with INFORMS Terms and Conditions for Use of Self-Archived Versions. 


\title{
Ride Your Luck! A Field Experiment on Lottery-based Incentives for Compliance*
}

\author{
Marco Fabbrił, Paolo Nicola Barbierił, Maria Bigoni ${ }^{\S}$
}

\begin{abstract}
In a field experiment, we studied the performance of an incentive scheme which combines a lottery-based reward for compliance with probabilistic sanctions for non-compliance. For one month, bus passengers who purchased a ticket on board a subset of buses operating in a medium size Italian city, participated in a lottery awarding a $€ 500$ prize. The remaining buses - otherwise identical - were used as controls. We observed the amount of tickets sold on treated and control buses over three months, before, during and after the introduction of the lottery. Results show that treated buses sold significantly more on-board tickets than control buses during the lottery period. In our set-up, the estimated extra-revenues from the ticket sales caused by the introduction of the lottery fell short of the amount of the total prizes raffled off. However, the incentive scheme proved cost-effective because not all the lottery prizes were claimed by winners.
\end{abstract}

\section{JEL-Classification: D04; H42}

Keywords: Enforcement; Fare-dodging; Public Good; Randomized Control-Trial; Risk Attitudes; Sanctions.

${ }^{*}$ We are grateful to the International Foundation for Research in Experimental Economics and its president Vernon Smith for generous financial support. Marco Fabbri is grateful to the research program Behavioural Approach to Contract and Tort at Erasmus University Rotterdam for providing financial support during the completion of the research. A special thank goes to the aldermen of the city of Rimini, Roberta Frisoni and Gianluca Brasini, to the President of START Romagna, Marco Benati, and to the President of Agenzia Mobilitá, Massimo Paganelli, who made this research possible, and to the employees of START Romagna for their support in the data collection. We also thank Ian Ayres, Stefania Bortolotti, Marco Casari, Giuseppe Dari-Mattiacci, Michael Faure, Sven Hoeppner, Rosemarie Nagel, Matteo Rizzolli, Massimiliano Vatiero, Louis Visscher and seminar and conference participants at universities UV Amsterdam, Bologna, Harvard, Lugano, Rotterdam, Vienna, and Pompeu Fabra. The usual disclaimer applies.

${ }^{\dagger}$ Principal Investigator and Corresponding author. University of Amsterdam, School of Law, Nieuwe Achtergracht 166, Room A5-15, 1018WV Amsterdam, The Netherlands, E-mail: m.fabbri@uva.nl, Telephone: $(+31)$ 024082843

${ }^{\ddagger}$ Centre for Health Economics, School of Business, Economics and Law, University of Gothenburg

${ }^{\S}$ Department of Economics, University of Bologna 


\section{Introduction}

Providing optimal incentives to encourage compliance is of primary importance for a wide array of situations where the players involved have conflicting interests. For instance, the tax authority aims to achieve taxpayers' compliance with tax regulations, law enforcement agencies want citizens to abide by laws and regulations, and employers want employees to offer an optimal performance. Compliance can be incentivized by means of either "sticks", like fines, damage charges, and imprisonment, or "carrots", such as bonuses and rewards, or by combining both tools (Andreoni et al., 2003, Fehr and Schmidt, 2007, Gürerk et al., 2006, Nosenzo et al., 2015, Sefton et al., 2007). Understanding how incentives affect behaviors in practice is a key objective since ill-designed incentives may be ineffective, causing a waste of resources, and possibly even counter-productive, undermining internal motivation and generating crowding-out effects (Bowles and Hwang, 2008, Gneezy and Rustichini, 2000, Mellström and Johannesson, 2008).

In this paper we contribute to the literature focusing on the optimal provision of incentives by studying -in a field experiment- the performance of a lottery awarding rewards for compliance with legal regulations, in combination with a probabilistic sanction for non-compliance. Lotteries are widely used by private companies to reinforce customer brand loyalty and increase their revenue (Mazar et al., 2016, Thaler and Ziemba, 1988). Traditionally, governments and other organizations have used lotteries to finance public goods (Clotfelter and Cook, 1991). In recent years, the use of policies based on lottery incentives has also extended to other domains such as tax evasion, savings, and education (Fabbri, 2015, Haisley et al., 2008). However, while the appeal and popularity of lotteries are undeniable and they are increasingly used by public and private organizations, only a few empirical studies (reviewed in the next section) have investigated the effects of using lotteries in reward systems, and their results have been mixed.

We contribute to this strand of literature by conducting a field experiment in the context of local public transportation. The public bus transportation system studied is available for all to use, but passengers are expected to pay a fare. Bus riders are randomly monitored, and faredodgers caught red-handed are subject to a penalty. In our experiment we complemented the deterrence approach based on probabilistic sanctions commonly employed by the bus company with rewards. In practice, we rewarded individuals' compliance -namely the purchase of a valid bus ticket- with a lottery ticket. In collaboration with the public company that manages the local bus transportation, we designed a randomized control-trial based on the introduction of a sequence of three lotteries awarding a total of six prizes within a one-month period, where participation is linked to the on-board purchase of bus tickets. We implemented the lotteries only for a subset of otherwise identical city buses operated by the local bus company. As explained in detail in the next section, we made sure that the buses participating in the lotteries ("treated buses") are not distinguishable from other buses ("control buses") from the outside. 
Our incentive scheme targeted occasional bus riders without either a seasonal ticket or a ticket bought before boarding and who, once they are on the bus, face the choice of either purchasing an on-board ticket or dodging the fare. In Appendix $\mathrm{C}$ we show that under certain assumptions, the lottery-based incentive generates an increase in total revenues that completely covers the cost of the prizes. To estimate the effects of the lottery on the number of tickets sold on-board, we obtained detailed information on the route to which each bus was assigned at each hour of a day. We then compared the number of on-board ticket sales on control and treated buses, by bus route, day, and time of day. Results show that, during the experimental period, the number of tickets sold on board the buses participating in the lottery was significantly higher than in the control sample. We then checked whether the incentive scheme brought about a reduction in off-board ticket sales because passengers substituted off-board tickets -which were not associated with the lottery- with on-board ones. Overall, we found no evidence of side effects on off-board sales. A more in-depth analysis revealed that the lottery reduced off-board sales for bus routes in suburban areas, which are characterized by infrequent runs clustered around peak hours on workdays, and are used predominantly by commuters.

The cost effectiveness of the lottery-based incentive scheme in our experiment remains unclear. On the one hand, the increased revenue from on-board ticket sales, generated by the three lotteries, more than covered the cost of the prizes paid out. On the other hand, this was true only because four out of six lottery winners did not claim their winnings. Had all six winners claimed their prizes, the increased profit for the company would not have sufficed to cover the costs incurred. The question remains open whether a lottery design that decreases transaction costs for the collection of monetary prizes (for instance, by introducing a mechanism that identifies and rewards the winner right after the ticket purchase) would modify the conclusions as to the cost-effectiveness of the incentive scheme. Indeed, such a design would increase the costs for paying prizes out but, at the same time, the more salient lottery would be likely to encourage other potential fare-dodgers to purchase a ticket.

In this study, we focused on small infractions that are very common in daily life, and yet can generate sizable costs for society (Fürst, 2012, Mazar and Ariely, 2006). The results shed light on the performance of lottery-based incentives for compliance combined with probabilistic sanctions, in a context akin to many other situations in which agents face compliance decisions, such as asking sellers to give them receipts for purchases of goods and services, or paying parking fares. These factors increase the generalizability of our results and the scope of their implications, since the effectiveness of incentives depends greatly on the conditions and domains of their application (Gneezy et al., 2011).

The paper is structured as follows. In the next section, we provide an overview of the related literature. Section 3 describes the experimental design. Section 4 lists the results, and Section 5 discusses the findings obtained, possible limitations, and targets for future researches. Section 6 offers our conclusions. 


\section{$2 \quad$ Related Literature}

Our study is related to two main strands of literature. First, we are contributing to the line of research that investigates the use of lotteries as a reward for compliance with rules and regulations, in combination with sanctions targeting non-compliant agents. Second, and more generally, our paper is connected to the literature on the effectiveness of financial incentives for behavior changes.

\section{Lottery Incentives for Compliance}

Contribution to public goods. Several laboratory and field studies have focused on the effects of monetary incentives in the form of lottery prizes for the provision of a public good, and reported mixed results. Some works confirmed the theoretical predictions put forth by Morgan (2000), i.e. that introducing a stochastic reward for public good contributions leads to a net increase in the related revenues, compared to the baseline voluntary contribution mechanism (Landry et al., 2006, Lange et al., 2007, Morgan and Sefton, 2000). However, in a laboratory experiment characterized by the simultaneous presence of possibilities for peer punishment and lottery rewards - a design that more closely resembles the set-up of our field experiment Fuster and Meier (2010) showed that monetary rewards crowd-out peers' willingness to punish, thus offsetting the effects of linking lottery prizes to public good provision. Other studies based on laboratory experiments have investigated the effects of centralized punishment subjected to random monitoring as an incentive for compliance (i.e. Nalbantian and Schotter, 1997), and decentralized punishment with imperfect monitoring (i.e. Ambrus and Greiner, 2012). Our paper differs from the aforementioned works in that we studied the performance of lottery rewards coupled with the presence of sanctions that are conditional on random monitoring for non-compliance. Moreover, compared to Fuster and Meier (2010) who also combine lottery rewards and deterministic peer punishment, we operated in a field-experimental setting and studied the simultaneous effects of centralized probabilistic sanctions and decentralized peer punishments.

Tax compliance. One strand of literature investigates the effects of stochastic monetary rewards on compliance with tax regulations. In a laboratory experiment, Alm et al. (1992) found that a mix of probabilistic rewards and sanctions maximizes net tax revenue. In a field experiment, Torgler (2003) confirmed the effectiveness of rewards in the form of monetary lottery prizes for increasing tax compliance. However, the external validity of these results remains unclear, since the study is characterized by a small sample size and its observations were collected in a single village in Costa Rica.

In contrast with these studies, in a field experiment involving tax payments financing religious activities in Germany, Dwenger et al. (2016) found that providing monetary incentives 
in the form of lottery prizes for compliance with a poorly-enforced 11 tax legislation does not increase tax revenues. The results of this study show that the lottery reward has opposite effects on baseline compliant agents (who increase compliance) and baseline evaders (who evade higher portions of owed taxes). The Authors suggest that while the lottery prize on the one hand reinforces the warm glow for compliance experienced by law-abiding agents, on the other hand, it downplays the mandatory aspect of a legally binding tax system for non-compliant ones.

Naritomi (2013) analyzed the use of lottery incentives for decentralized enforcement of tax regulations by looking at the introduction of a tax lottery in the state of São Paulo, Brazil. Tax lotteries aim at rewarding consumers for acting as third-party tax enforcers by providing incentives for customers to ask "forgetful" business owners for receipts for their purchases, which record the VAT payments. The Author showed that the tax lottery introduced significantly increased VAT collection, while the increase in tax revenue generated by the lottery more than compensated for the payments of monetary prizes.

Voter Registration and Voting Participation. Two recent contributions in the political science literature used field experiments to study the effects of monetary incentives distributed as lottery prizes to increase voters' mandatory registration on the electoral rolls and voting turnover. Koelle et al. (2017) showed that voter registration increases when the possibility of being sanctioned is emphasized, while a reward -i.e. a small monetary prize awarded by lotteryfor complying with the registration requirement has no effect. Other studies investigated the use of monetary lottery rewards on voting behavior and found: (i) a significant but small $(2 \%)$ increase in voter registration (John et al. 2015$)$ and (ii) a significant increase in voting turnout only when nontrivial monetary prizes are awarded (Panagopoulos, 2012).

We complement these studies by providing novel evidence on the effects of lottery-based rewards on the compliance with a legal requirement, based on a field experiment. We believe our results are easier to generalize, compared to those from experiments on voting behavior, since fare-dodging is a very common transgression in everyday life, which correlates well with other forms of cheating in laboratory experiments (Dai et al., 2017). For a more extensive review of the literature, we suggest the works by Balliet et al. (2011) and Kraft-Todd et al. (2015), which also provide evidence of contradictory results. While the former focuses on laboratory experiments, and suggests that monetary incentives are effective promoters of cooperation in social dilemmas, the latter presents an overview of field experiments on this issue, offering less clear-cut results on the effectiveness of material rewards in increasing cooperation.

\section{Incentives for Behavior Change}

Health behavior. In the area of health behavior changes, studies found that the provision of monetary compensations is effective in promoting healthy behaviors such as regular gym

\footnotetext{
${ }^{1}$ The authors emphasize that in the context of their experiment, the payment of religious taxes, while formally mandatory, was de facto never enforced.
} 
attendance, weight loss, and smoking cessation (Acland and Levy, 2010, Babcock and Hartman, 2010, Cawley and Price, 2009, Charness and Gneezy, 2009, Volpp et al., 2009). A recent review of the medical literature confirmed these findings across several domains of health behavior (Giles et al. 2014). The introduction of monetary incentives in the form of a lottery seems to be particularly effective for reducing involuntary missed drug ingestion for chronic diseases (Volpp et al., 2008) and for encouraging safe sexual behaviors (Bjorkman Nyqvist et al., 2015).

Education. The effectiveness of monetary incentives in the area of education seems to vary according to the type of incentive provided. Studies investigating the performance of monetary incentives for school attendance generally report successful results in increasing children's enrollment in school programs, and in reducing the drop-out rate, at least in the short term Angrist and Lavy, 2009, Schultz, 2004). Conversely, results are mixed when the incentives provided are conditional on performance (Bettinger, 2012, Fryer Jr, 2011). In a recent study, Levitt et al. (2016) confirmed that the overall impact of incentives is modest and fades away over the longer term. However, the Authors emphasize that incentives have large, significant, and persistent (up to several years after the program end) effects among students on the threshold for meeting the achievement standard. Levitt et al. (2016) also did not find an impact when varying the reward structure, whether fixed-rate or lottery.

Saving. Lottery rewards have been proven effective also in increasing savings (Kearney et al., 2010). For instance, Filiz-Ozbay et al. (2015) studied lottery-linked deposit accounts (also known as "prized-linked savings"), where the amount of deposits is tied to the chance of winning a potentially large prize in periodic lotteries. They found that these lottery-based incentives are highly effective in increasing the amount of private savings.

Our work differs from these contributions, in that we studied the offer of lottery incentives to encourage compliance with a predefined legal norm (the purchase of a valid bus ticket), whereas others focus on the promotion of behaviors that arguably increase the agents' personal well-being (healthier lifestyle, better education, higher saving rates). Moreover, in contrast with these studies, our field experiment looked at the joint effects of probabilistic sanctions and rewards.

\section{Experimental Design}

The experiment was conducted in the city of Rimini, Italy (population 146,000) in cooperation with Start Romagna SpA, the government-owned company providing local bus transportation, and Agenzia Mobilità, the local agency in charge of coordinating public transportation services in the Rimini province. The bus company has a total 299 buses operating in the Rimini municipality; all of them are identical except for their unique identifying serial number. Passengers can buy a ticket before or upon boarding a bus. In an attempt to limit opportunistic behavior, ticket inspectors randomly monitor travelers and sanction fare-dodgers. Despite 
this enforcement activity, however, a remarkable proportion of passengers ${ }^{2}$ continues to travel without tickets when using public bus transportation?

Passengers have the possibility to purchase weekly, monthly, or seasonal tickets. Bus riders who do not possess one of these tickets can purchase a standard hourly ticket off-board for a price ranging from $€ 1.00$ (each, in a book of 10 tickets) to $€ 1.20$ (for a single ticket). 4 Alternatively, a ticket can be purchased on board for a price of $€ 2.00$ using an automatic machine installed on each bus. The fine for free riders amounts to $€ 65$ if paid within 5 days, $€ 80$ if paid between 6 and 60 days after the sanction, and $€ 240$ if paid after more than 60 days.

Our experiment focused on passengers who boarded a bus without a previously purchased ticket and who face the choice of either buying an on-board ticket using the ticket vending machine or fare-dodging. We advised Start Romagna during the organization of a lottery in which participation was linked to the purchase of on-board tickets. From the sample of identical buses operating in Rimini, we randomly selected a subsample of 54 which we will refer to as the "treated" buses. Inside each of these 54 buses, we affixed posters informing customers that if they bought a ticket on board, they would be eligible to participate in a lottery (an example of posters advertising the lottery is included in Appendix A). To avoid the insurgence of experimental demand and Hawthorne effects, we presented and promoted the lottery as a "marketing strategy" implemented by the bus company to reward compliant customers rather than as an experiment run for scientific purposes. Therefore, during the lottery promotional campaign and in the content of the informative posters and flyers, we carefully avoided mentioning the scientific nature of the research. In order to rule out the possibility of passengers self-selecting treated buses, we designed and placed posters and flyers in such a way as to make it impossible for passengers to see them before getting on-board. Thus, treated and control buses could not be identified from the outside. Another reason why the self-selection of passengers on treated buses was unlikely is the relatively low frequency of vehicles running the same route in the city. For most of the routes, the time interval between two buses ranges between 15 and 30 minutes on weekdays on urban routes, and up to one hour either on suburban routes or on urban routes at night and in weekends, making it unrealistic to imagine that a passenger waiting at a bus stop would only board if the bus belonged to the treated group.

We randomly selected six tickets among those sold on board the treated buses during the

\footnotetext{
${ }^{2}$ Start Romagna estimates that the rate of fare-dodging in 2013, calculated by comparing the number of users of a bus and the revenue from the tickets sold on that bus (also taking into account that a fraction of bus users has seasonal tickets) was between $30 \%$ and $50 \%$.

${ }^{3}$ An alternative strategy for preventing fare-dodging adopted in some countries consists of admitting on board only passengers with a regular ticket or passengers who purchase a ticket directly from the driver. This solution was attempted for a period in Rimini and other Italian cities. However, it was quickly abandoned due to its associated costs: the queue of passengers wanting to purchase tickets on board created continuous delays and traffic jams in the narrow medieval streets that characterize most Italian cities.

${ }^{4}$ Off-board tickets can be easily purchased in designated shops located at the main bus stations, kiosks, supermarkets, retail shops, coffee bars, and tobacco shops. Off-board tickets are therefore available in the immediate proximity of virtually any bus stop served in the area.
} 
period between November 15 and December 15, 2014. These tickets would each be associated with a lottery prize worth $€ 500$. Three lotteries, each one distributing two identical prizes, were organized 5 To identify lottery winners, we used the serial number of each ticket purchased on board. In the days following the end of each of the three lottery periods, two serial numbers were drawn from the list of all the on-board tickets sold in the treated sample. The owner of the ticket with the corresponding serial number printed on it was entitled to claim the prize. To verify the effects of the lottery on on-board ticket sales, we compared on-board sales on treated and control buses during the lottery period, and during the previous and following months, as further explained in Section 4.

One potential problem of the experimental design for estimating the net effect of our incentive is that it was focused only on the sample of tickets purchased on-board. Indeed, it is possible that during the lottery period passengers traveling on treated buses started substituting tickets purchased off-board with on-board tickets in order to participate to the lottery. 6 Moreover, it is possible for the introduction of a monetary incentive for compliance with the ticket purchase requirement to backfire. In particular, passengers who had purchased an offboard ticket before catching the bus - as the company encourages to do so in its informational campaigns to encourage compliance - and would be willing to use it, could react negatively to the announcement of a lottery prize benefiting those passengers who enter the bus without having a ticket. These passengers might then decide to fare-dodge by not stamping the offboard ticket as a retaliation against the company's decision to introduce the lottery. Should a substitution of off-board with on-board tickets or a negative reaction to the introduction of the lottery be the only effects caused by the incentive scheme, focusing on data regarding on-board sales would suggest increased sales for treated buses but, as a matter of fact, this increase is not due to the reduction of fare-dodging. Therefore, we also tested whether the incentive scheme causes substitution or side effects by checking to see whether the lottery introduction affected

\footnotetext{
${ }^{5}$ Two winning tickets were sold during the period November 15-21, two during the period November 22December 1, and two during the period December 2-15.

${ }^{6}$ While it is fundamental for our analysis to check for possible substitution effects, it should be pointed out that there are good reasons for rational passengers not to substitute off-board with on-board tickets. First, for a price corresponding to the surcharge for purchasing tickets on board, the Italian government offers a wide array of gambling products, all of which are characterized by a higher expected payoff and direct cash compensation. The existence of these gambling opportunities is well known, their use is widespread, and these products are also available in the same locations where off-board tickets can be purchased. Cash prizes make standard gambling products even more appealing than our lottery, since the Italian regulation on gambling activities forbids monetary prizes as compensation for lotteries organized by limited companies such as Start Romagna; therefore, our prize consisted of a voucher to be spent in a well-known chain store. Second, compared to our bus lottery, these low-cost gambling products have significantly lower costs for checking actual winnings and collecting prizes. Our bus lottery required the passenger to keep the used tickets up to the end of the lottery period; check for the results of the lottery online, on the news, or on posters located at bus stops; and then go in person to the bus company office to collect the prize. Conversely, the low-cost gambling products can be scratched right away after purchase, and winnings up to $€ 1,000$ can be collected in cash directly from the shop owner. Finally, while the prize of the bus lottery is subject to time discounting, because of the time delay between ticket purchase and lottery drawing, the outcome of the low-cost gambling can be seen immediately after the purchase.
} 
off-board sales.

If, during the lottery period, the treated buses showed an increased amount of on-board tickets sold which, net of substitution or side effects, is sufficient to cover the lottery costs, we can claim that the incentive scheme leads potential fare-dodgers to purchase on-board tickets.

\section{Results}

Figure 1 shows the average number of tickets sold on-board and off-board on a daily basis, during the lottery period and in the previous and following months. During the lottery period, the number of tickets sold per day on board the treated buses was approximately twice those sold on board control buses. In the months before and after the lottery, the difference in onboard daily sales was much smaller. The figure also shows that off-board sales represent the majority of total sales and that, before the lottery, the number of tickets sold off-board was slightly higher on the control than on the treated buses.

We estimated the effects of the lottery introduction on the number of on-board tickets sold as follows. From the archives of the bus company we collected detailed information on the specific route and timetable to which each bus was assigned on any given day. Then, for each bus in the sample, we counted the number of the on-board and off-board tickets sold in a one-hour time slot. 7 These measures constitute our unit of observation in the analysis reported below.

We started the analysis by estimating the lottery effects on the tickets sold on-board. To do so, we compared on-board sales on treated and control buses during the lottery period and during the months before and after the introduction of the incentive scheme. As a preliminary check, we had to verify whether in the month preceding the lottery introduction the trends of on-board and off-board ticket sales were the same on the treated and control buses. Testing whether the parallel trend assumption holds in our sample is fundamental for ensuring the internal validity of the Difference-In-Difference models we adopted to estimate the treatment effect. The results of this preliminary check are shown in Table ?? of Appendix A. We regressed the sales_onboard (Models 1-2) and sales_of fboard (Models 3-4) variables on the interaction term between treated and the variable day, indicating the day of the month, using data from the period before the lottery. The regression included bus-line and hour of the day fixed effects. Standard errors are clustered at the bus-line level. Results show that the pre-treatment trend for both on-board and off-board ticket sales was the same for the treated and control samples alike.

\footnotetext{
${ }^{7}$ To become valid travel documents for a journey on a specific time-route, otherwise identical tickets purchased off-board have to be stamped by the passengers using dedicated machines (different from those used for selling on-board tickets) placed inside each bus. These machines record the time and bus route for which the ticket is valid. Considering this, we named - slightly improperly - our outcome variable sales off-board, since what we are observing is the bus, time, and route on which a ticket, previously purchased off-board, is actually used by a passenger.
} 


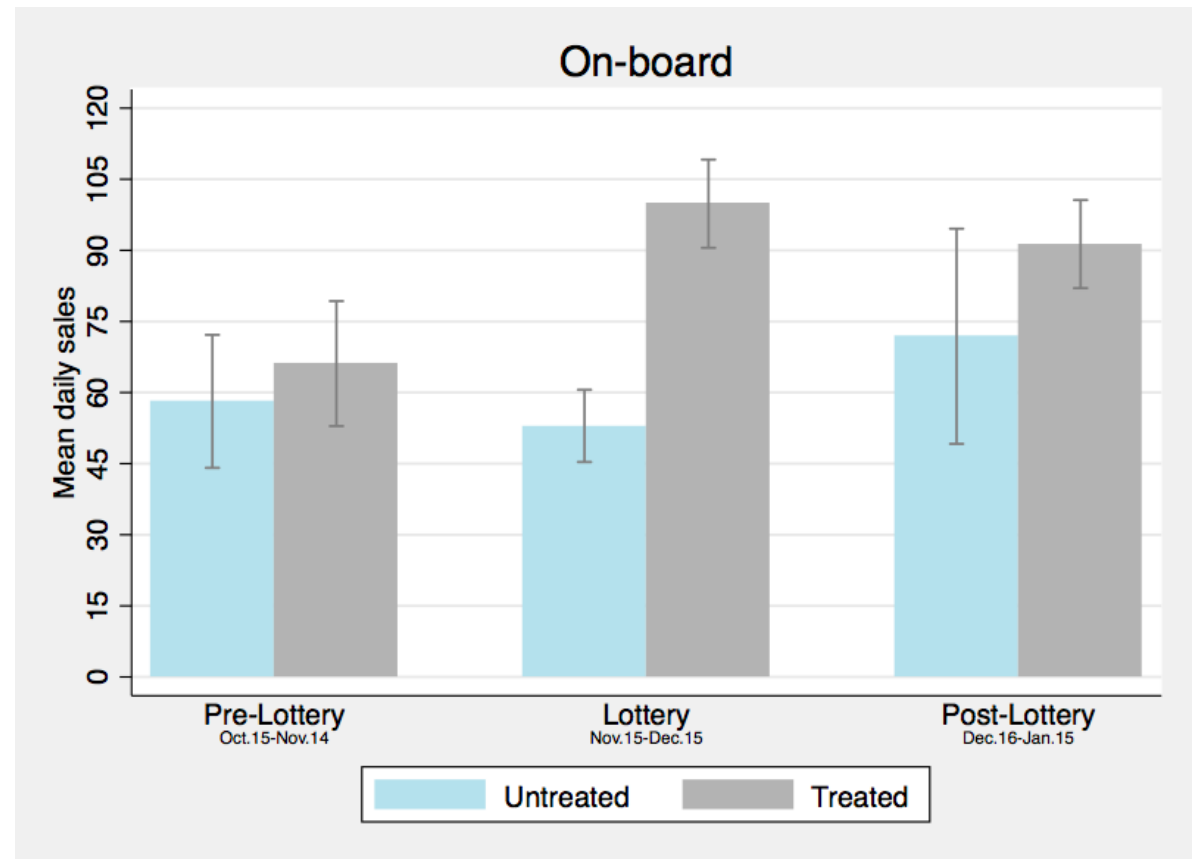

(a) Sales on-board

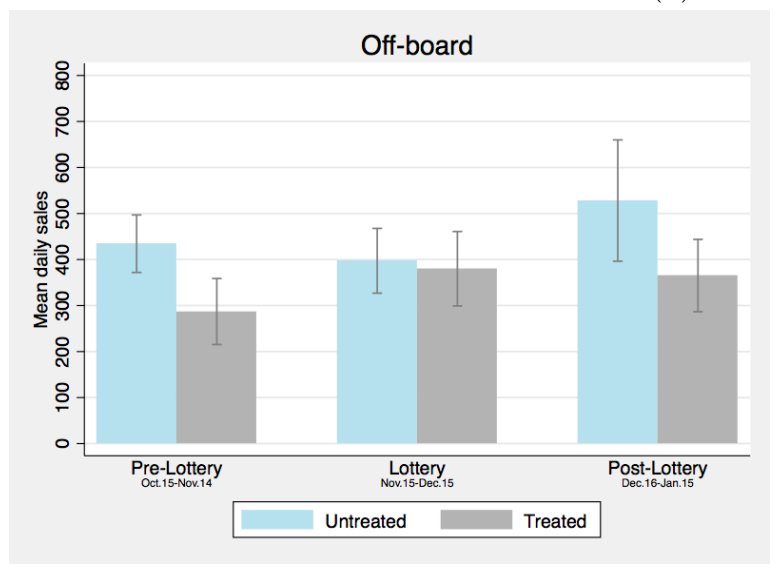

(b) Sales off-board

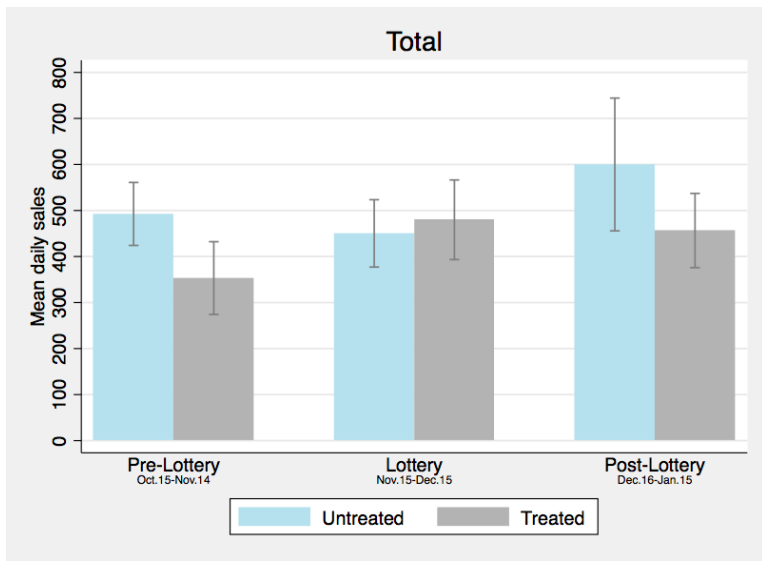

(c) Total sales

Figure 1: Daily ticket sales

We then tested the lottery effect by regressing sales_onboard on a dummy for treated buses and we interacted it with dummies for the lottery period and the following month, controlling for day, hour of the day, and bus-line fixed effects. The pre-lottery period is the base category. Standard errors are clustered by bus-line. Table 1 shows the results. In model 1 we included the whole sample of one-hour slots when buses were operating. The main coefficient of interest for our analysis is that of the interaction term treated $\times$ lottery. The estimated coefficient is positive and significant at the $1 \%$ level, thus suggesting that the incentive scheme determined an average increase of 0.064 on-board tickets per hour. The significant increase in on-board 
Table 1: On-board tickets sales, OLS regression

\begin{tabular}{|c|c|c|c|c|}
\hline & Model 1 & Model 2 & Model 3 & Model 4 \\
\hline \multirow[t]{2}{*}{ treated } & $0.072^{* *}$ & 0.023 & $0.071^{* *}$ & 0.026 \\
\hline & $(0.027)$ & $(0.079)$ & $(0.030)$ & $(0.084)$ \\
\hline \multirow[t]{2}{*}{ lottery } & $-0.179^{* *}$ & $-0.549^{* * *}$ & $-0.179^{*}$ & $-0.565^{* * *}$ \\
\hline & $(0.086)$ & $(0.151)$ & $(0.088)$ & $(0.144)$ \\
\hline \multirow[t]{2}{*}{ post-lottery } & $-0.276^{* * *}$ & $-0.636^{* * *}$ & $-0.275^{* * *}$ & $-0.657 * * *$ \\
\hline & $(0.087)$ & $(0.142)$ & $(0.089)$ & $(0.133)$ \\
\hline \multirow[t]{2}{*}{ treated $\times$ lottery } & $0.064^{* * *}$ & $0.120^{* * *}$ & $0.073^{* * *}$ & $0.118^{* * *}$ \\
\hline & $(0.014)$ & $(0.037)$ & $(0.014)$ & $(0.040)$ \\
\hline \multirow[t]{2}{*}{ treated $\times$ post-lottery } & $0.053^{* *}$ & 0.085 & $0.063^{* * *}$ & 0.089 \\
\hline & $(0.021)$ & $(0.058)$ & $(0.020)$ & $(0.062)$ \\
\hline \multirow[t]{2}{*}{ suburban $=1$} & & & -0.018 & $-0.298^{* * *}$ \\
\hline & & & $(0.042)$ & $(0.078)$ \\
\hline \multirow[t]{2}{*}{ treated $\times$ suburban $=1$} & & & 0.005 & -0.013 \\
\hline & & & $(0.039)$ & $(0.133)$ \\
\hline \multirow[t]{2}{*}{ lottery $\times$ suburban $=1$} & & & 0.004 & $0.092^{* * *}$ \\
\hline & & & $(0.017)$ & $(0.032)$ \\
\hline \multirow[t]{2}{*}{ post-lottery $\times$ suburban $=1$} & & & -0.004 & $0.131^{* * *}$ \\
\hline & & & $(0.027)$ & $(0.043)$ \\
\hline \multirow[t]{2}{*}{ treated $\times$ lottery $\times$ suburban $=1$} & & & -0.059 & -0.004 \\
\hline & & & $(0.035)$ & $(0.086)$ \\
\hline \multirow[t]{2}{*}{ treated $\times$ post-lottery $\times$ suburban $=1$} & & & $-0.085^{* * *}$ & -0.071 \\
\hline & & & $(0.029)$ & $(0.112)$ \\
\hline \multirow[t]{2}{*}{ Constant } & -0.147 & 0.172 & -0.166 & 0.189 \\
\hline & $(0.116)$ & $(0.258)$ & $(0.122)$ & $(0.262)$ \\
\hline Time of the day f.e. & Yes & Yes & Yes & Yes \\
\hline Line f.e. & Yes & Yes & Yes & Yes \\
\hline Day f.e. & Yes & Yes & Yes & Yes \\
\hline N.obs. & 64714 & 20284 & 64714 & 20284 \\
\hline
\end{tabular}

Notes: Dependent variable: on-board tickets sales. OLS regressions, with line, time of day, and day fixed effects. Standard errors robust for clustering at the line level. Model 1 includes the full sample, Model 2 considers the restricted sample of hourly time slots during which at least one ticket was sold, either on or off-board. Model 3 isolates the effects of buses traveling on urban routes and suburban routes, respectively; Model 4 isolates the effects of buses traveling respectively on urban routes and suburban routes and considered the restricted sample of hourly time slots during which at least one ticket was sold. Symbols $* * *, * *$, and $*$ indicate significance at the $1 \%, 5 \%$ and $10 \%$ level, respectively.

tickets sold during the lottery period is also confirmed in model 2 (p-value $<1 \%$ ), in which we included only hourly slots during which at least one ticket (either on-board or off-board) was sold. The coefficient of the interaction term treated $\times$ lottery suggests an increase of 0.118 on-board tickets sold per hourly slot. Considering that - in the whole sample - on-board sales amounted to 0.208 tickets and that this quantity rose to 0.662 in the restricted sample, the reported coefficients translate respectively into a $30 \%-18 \%$ estimated increase in on-board 
sales produced by the incentive scheme 8

It is worth noting the positive coefficients of the variables treated and treated $\times$ lottery in model 1, which suggest that on-board sales in the sample of treated buses were significantly higher for treated buses than control buses in all periods of the study. This result, however, does not affect the validity of our diff-in-diff approach, since the baseline category of comparison included the sample of treated buses in the pre-lottery period. Moreover, when we consider the restricted sample of hourly slots during which at least one ticket was sold either on-board or off-board, the differences in on-board sales between treated and control buses disappears, while our main results are confirmed.

We continued the analysis by checking whether passengers traveling on bus routes serving the urban area of the municipality reacted to the introduction of the lottery the same way as passengers traveling on suburban routes did. Bus services for suburban routes are fewer compared to urban ones, and concentrated during peak hours of workdays. Services operating outside working hours, or during evenings and weekends are rare. Therefore, buses in suburban areas are ridden mostly by passengers using public transportation to commute to work, school or other businesses in the city. Conversely, the occasional bus passengers riding on urban routes can count on more frequent bus services running also at night and on weekends. These passengers can use public transportation for a wider range of purposes, including recreational activities. Figure ?? in Appendix A plots the average on-board sales at different hours of the day. While buses in suburban bus routes sell virtually no tickets in the evening and outside of working hours, on urban bus routes a sizeable amount of tickets is sold throughout the whole day, including evenings and night hours. Given these differences between the bus service offered in urban and suburban areas, it might be possible that passengers' individual characteristics, mood, and emotional state - and therefore their reaction to the lottery-based incentive - are different in the two scenarios.

To verify whether this was the case, in models 3 and 4 we introduced the dummy Suburban equal to one for bus routes operating in the rural area and we interacted it with the other main regressors. As before, in model 3 the whole sample of one-hour slots is considered, while model 4 is restricted to hourly slots during which at least one ticket was sold. The coefficient of the interaction term treated $\times$ lottery, that in models 3 and 4 isolates the effects of the lottery on the tickets sold on-board in urban routes, is positive and statistically significant at the $1 \%$ level, thus suggesting an increase of 0.073 and 0.118, respectively, in on-board sales per hour. The coefficient of the interaction between the dummy variable identifying suburban routes and treated $\times$ lottery in models 3 and 4 is never statistically different from zero, suggesting that the effect of the lottery on on-board sales was approximately the same in urban and suburban

\footnotetext{
${ }^{8} \mathrm{We}$ also checked whether the effect of the lottery on on-board sales varied between the initial and final period of implementation of the incentive scheme. To do so, we replicated models 1 and 2 described in Table 1 but including only either the initial or the final 15-day period of the lottery implementation. Results shown in Table ?? in Appendix A indicate that there is no significant difference between these two periods.
} 
areas.

In summary, our results indicate that the introduction of the lottery incentive caused a significant increase in the amount of on-board ticket sales, compared to off-board sales.

Table 2: Off-board tickets sales, OLS regression

\begin{tabular}{|c|c|c|c|c|}
\hline & Model 1 & Model 2 & Model 3 & Model 4 \\
\hline \multirow[t]{2}{*}{ treated } & $0.284^{* *}$ & -0.043 & $0.312^{* *}$ & -0.081 \\
\hline & $(0.118)$ & $(0.303)$ & $(0.142)$ & $(0.311)$ \\
\hline \multirow[t]{2}{*}{ lottery } & $-0.429 * *$ & -1.102 & $-0.386^{*}$ & -1.186 \\
\hline & $(0.189)$ & $(0.960)$ & $(0.210)$ & $(0.944)$ \\
\hline \multirow[t]{2}{*}{ post-lottery } & $-0.724^{* * *}$ & -0.845 & $-0.617^{* *}$ & -0.837 \\
\hline & $(0.223)$ & $(1.015)$ & $(0.285)$ & $(1.014)$ \\
\hline \multirow[t]{2}{*}{ treated $\times$ lottery } & -0.029 & -0.149 & 0.011 & -0.064 \\
\hline & $(0.067)$ & $(0.215)$ & $(0.071)$ & $(0.222)$ \\
\hline \multirow[t]{2}{*}{ treated $\times$ post-lottery } & -0.166 & -0.544 & -0.193 & -0.558 \\
\hline & $(0.322)$ & $(0.481)$ & $(0.389)$ & $(0.531)$ \\
\hline \multirow[t]{2}{*}{ suburban $=1$} & & & 0.055 & $-1.000 * *$ \\
\hline & & & $(0.185)$ & $(0.453)$ \\
\hline \multirow[t]{2}{*}{ treated $\times$ suburban $=1$} & & & -0.180 & 0.360 \\
\hline & & & $(0.294)$ & $(0.387)$ \\
\hline \multirow[t]{2}{*}{ lottery $\times$ suburban $=1$} & & & -0.049 & $0.606^{*}$ \\
\hline & & & $(0.099)$ & $(0.338)$ \\
\hline \multirow[t]{2}{*}{ post-lottery $\times$ suburban $=1$} & & & -0.391 & -0.174 \\
\hline & & & $(0.326)$ & $(0.458)$ \\
\hline \multirow[t]{2}{*}{ treated $\times$ lottery $\times$ suburban $=1$} & & & $-0.321^{*}$ & $-0.734^{* *}$ \\
\hline & & & $(0.167)$ & $(0.294)$ \\
\hline \multirow[t]{2}{*}{ treated $\times$ post-lottery $\times$ suburban $=1$} & & & 0.058 & 0.258 \\
\hline & & & $(0.463)$ & $(0.647)$ \\
\hline \multirow[t]{2}{*}{ Constant } & 0.272 & $5.289^{* * *}$ & 0.102 & $5.396^{* *}$ \\
\hline & $(0.637)$ & $(1.875)$ & $(0.660)$ & $(1.988)$ \\
\hline Time of the day f.e. & Yes & Yes & Yes & Yes \\
\hline Line f.e. & Yes & Yes & Yes & Yes \\
\hline Day f.e. & Yes & Yes & Yes & Yes \\
\hline N.obs. & 64714 & 20284 & 64714 & 20284 \\
\hline
\end{tabular}

Notes: Dependent variable: off-board tickets sales. Linear regressions, with line, time of day, and day fixed effects. Standard errors robust for clustering at the line level. Model 1 includes the full sample, Model 2 considers the restricted sample of hourly time slots during which at least one ticket was sold, either on or offboard. Model 3 isolates the effects of buses traveling on urban routes and suburban routes respectively; Models 4 isolates the effects of buses traveling on urban routes and suburban routes and considers the restricted sample of hourly time slots during which at least one ticket was sold. Symbols $* * *, * *$, and $*$ indicate significance at the $1 \%, 5 \%$ and $10 \%$ level, respectively.

We then investigated whether the incentive scheme had produced side-effects on the offboard ticket sales that were not targeted by the lottery. Indeed, it is possible that the observed increase in on-board ticket sales was caused by passengers substituting off-board tickets with 
on-board ones, because they wanted to participate to the lottery. Moreover, the introduction of the lottery might have triggered passengers' negative reactions, leading to fare-dodging of occasional riders who, absent the lottery, would have used off-board tickets. For this particular investigation, we repeated the analysis reported above considering hourly sales of off-board tickets during the lottery period and during the previous and following months.

As a preliminary step we checked whether, in the month preceding the introduction of the lottery, the trend of off-board sales was the same on treated and control buses. Results are shown in models 3 and 4 of Table ?? in Appendix A. Model 4 differs from model 3 because it includes a dummy for suburban lines. Our results confirm that the pre-treatment trends of off-board sales were statistically the same for treated and control buses.

We then estimated the effects of introducing the incentive scheme on off-board tickets using an OLS regression. As before, we regressed off-board sales in the lottery phase and in the preceding and following phases on the dummy treated, and we included fixed effects for day, hour of the day, and bus-route. Standard errors are clustered at the bus-route level. Results in Table 2 report the estimations of the lottery effect on off-board sales.

In model 1 we used the whole sample of one-hour slots. We focus on the interaction between the dummies treated and lottery, indicating respectively the buses belonging to the treated sample and the phase corresponding to the lottery period. The estimated coefficient is not statistically different from zero, thus suggesting that the introduction of the incentive scheme targeting on-board tickets had no effects on off-board sales. The same is true for the coefficient of the interaction term in model 2 , in which we restricted the sample to one-hour slots that sold at least one ticket.

In models 3 and 4 we verified whether passengers traveling on suburban routes showed a different reaction to the introduction of the lottery compared to passengers on urban routes. We replicated the regression presented in models 1 and 2, by adding the dummy suburban - which identifies the hourly slots during which a bus circulated on suburban routes - and its interaction with other main regressors. The coefficient of the interaction term treated $\times$ lottery, which isolates the effects of the incentive scheme on off-board sales in urban routes, remains statistically not different from zero in both models 3 and 4 . Conversely, the coefficient of the interaction term treated $\times$ lottery $\times$ suburban, indicating off-board sales on suburban routes, is negative and marginally significant in model 3 . The same negative coefficient becomes statistically significant at the $5 \%$ level in model 4 . Considering an average off-board sale of 1.13 tickets per hourly time slot (3.59 if we consider the restricted sample of hourly slots during which at least one ticket was sold), these results suggest that on suburban routes the incentive scheme targeting on-board tickets determined a $28 \%(20 \%)$ decrease in off-board sales.

In conclusion, during the lottery period our results suggest a significant increase in the onboard sales rate. Overall, the introduction of the lottery targeting on-board tickets did not result in a reduction of off-board sales. If we separate the urban and suburban routes of the 
municipality, results suggest that the introduction of the incentive scheme on routes serving suburban areas caused a significant reduction of off-board ticket sales. 9

We also obtained data on the sanctions imposed during the lottery period and during the weeks following the end of the incentive. Several scenarios were possible. Passengers might have perceived that the introduction of the lottery was associated with a higher monitoring of faredodging by the bus company on either the treated buses or all buses. Moreover, passengers who knew about the lottery might have felt frustrated if they could not take part in it and reacted by not purchasing a ticket at all. This might have happened either because during the lottery period they had boarded a control bus, or because they reacted negatively to the removal of the incentive after the lottery end. Figure ?? in Appendix A plots the number of sanctions by treatment groups during the lottery period and in the following and previous months. Data do not show significant changes in either the number of sanctions imposed by the company or the number of tickets sold. The results from an OLS regression reported in Table ?? in Appendix A confirm the impression conveyed by the graph. However, we emphasize that the results on the effects of the lottery on sanctions must be read with caution and that we cannot draw any solid conclusions on the effects of the lottery on fare-dodging, since the bus company does not collect data regarding the number of passengers inspected and found compliant with travel rules.

Finally, we estimated whether the lottery was cost-effective. An on-board ticket has a unit cost of $€ 2$. According to the estimations in Table 1, the introduction of the lottery determined an increase of 0.064 on-board ticket sales per one-hour time slot. The period during which the lottery was implemented consisted of 21,807 one-hour slots. This translates in an estimated increase of roughly 1,396 on-board tickets sold, resulting in an increase in revenue of $€ 2,792$. Therefore, the estimated increase in revenue due to the lottery falls short of the total value of the six $€ 500$ prizes that was announced. Had each winner claimed the prize, the incentive scheme would have resulted in a net loss for the company. However, in our experiment the revenue generated by the lottery was above the value of the prizes that have been actually claimed by winners, since four out of six winners failed to cash in their reward 10

\section{Discussion}

The results presented in the previous section suggest that, in our experiment, the introduction of the lottery significantly increased on-board ticket sales. We also registered no overall variation in the sales of off-board tickets not participating in the lottery. In our experiment,

\footnotetext{
${ }^{9}$ As a robustness check, we replicated the analysis by implementing Poisson, Negative Binomial, and Zeroinflated Negative Binomial regressions. Results are shown in Tables ??, ??, and ?? in Appendix B and are qualitatively and quantitatively very similar to those obtained by using OLS.

${ }^{10}$ Under Italian regulation, lottery prizes not claimed could be used by the company to enrich the jackpot of subsequent lottery rounds. In the case of our experiment, uncollected prizes were donated to a local nongovernmental organization supporting people in need, hence the total cost associated with the lottery remained the same.
} 
the lottery proved to be self-financing, since the increase in revenue from ticket sales more than compensated for the prizes actually paid out. This result is consistent with the predictions of the model included in Appendix C.

However, it must be emphasized that the cost-effectiveness of the incentive scheme we studied remains unclear. The increase in profit fell short of the total amount of prizes raffled off, and the incentive scheme resulted cost-effective only because some winners did not claim their prizes. Failing to claim prizes - often much larger than the one offered by our bus lottery - is not uncommon among lottery winners. For instance, in the US, according to the Multi-State Lottery Association, in 2011 something like $\$ 800$ million went unclaimed nationwide, with cases as extreme as a single winner missing out on a $\$ 50$ million jackpot ${ }^{11}$ In addition to the lack of attention, a possible reason why some prizes were not claimed may be that in our experiment there were non-negligible transaction costs for participants, including the need to keep the ticket for days before the draw, verify the winning number, and collect the prize in person at the bus company office. It must be noted, however, that a design that reduces these transaction costs could result in a higher or lower cost-effectiveness. Indeed, while making it easier to identify the winner (i.e. by installing a device on buses that signals the winning ticket immediately when purchased) would increase the prize costs, at the same time it would also raise the lottery salience, thus convincing additional potential fare dodgers to buy bus tickets.

Moreover, in the specific context of our experiment, two additional considerations regarding the cost-effectiveness of the incentive scheme are in order. First, a company or a public authority that repeats a lottery for several periods might enhance its efficiency by calibrating the prize in order to maximize net revenues. Indeed, over time the lottery organizer would acquire information regarding the optimal combination of prize amount, probabilities of winning, and frequency of the lottery draws in order to maximize the appeal of the incentive scheme. Second, during a post-experiment interview conducted with the bus company managers, they highlighted an important additional benefit deriving from a reduction in the number of fare dodgers. Each endorsed sanction entails administrative costs for the bus company. However, a sizeable fraction of the total monetary amount deriving from sanctions is not actually collected. For instance, according to Start Romagna, in 2013 the percentage of fines imposed but not cashed in amounted to roughly $35 \%$ of the total. The problem arises in situations when, for instance, the sanctioned individual is either a destitute person or a resident in a foreign country. In cases where deterrence is not only ineffective, but also wastefully costly, a lottery-based incentive scheme might offer additional advantages to induce compliance.

An important issue for evaluating the incentive scheme analyzed concerns the sustainability of the mechanism and the persistence of the incentive effects. Previous studies showed that financial incentives may have long-lasting effects in coordination games (Brandts and Cooper, 2006), but the effects of negative incentives (i.e. peer punishment) or rewards for contributing

\footnotetext{
${ }^{11}$ For additional information see http://edition.cnn.com/2013/10/08/us/indiana-lottery-loser/index.html.
} 
to public goods do not persist upon removal (Bruttel and Friehe, 2014, Lefebvre et al., 2016). In our experiment, once the lottery incentive was removed it was unclear whether the effect of the intervention persisted to some extent. In our baseline OLS regression, the coefficient of the interaction variable treated $\times$ post - lottery in model 1 of Table 1 is positive and statistically significant, albeit smaller than during the lottery period. However, in model 2, where we included in the regression only the restricted sample of hourly slots in which at least one ticket was sold, the coefficient of the interaction term treated $\times$ post - lottery is not statistically different from zero, suggesting that on-board sales have reverted to the pre-lottery period. Similarly, the results of Poisson, Negative Binomial, and Zero-inflated Negative Binomial regressions reported in Tables ?? and ?? in Appendix B show that in the post-lottery period the effect of the intervention vanished completely. It can be expected that the persistence of the intervention effect is limited after the removal of the incentives, since one month is arguably too short a period to produce permanent changes in behavior, also considering that the incentive scheme in our experiment targeted occasional riders. Moreover, Hogarth and Villeval (2014) showed in a laboratory experiment that the removal of random positive incentives distributed at regular intervals determines a sharper drop in compliance compared to the case in which incentives are distributed at irregular intervals. Similarly, Dai et al. (2015) showed that the effects of negative incentives on compliance persist longer after being withdrawn if the incentives are provided at irregular time intervals. In our experiment, we distributed the random positive incentives at pre-determined, announced intervals, and we explicitly publicized the end of the lottery period. Therefore, this feature of our design further reduced the likelihood of observing any persistence of the incentive effects. More generally, our experiment was not designed, and data are not well suited, to answer questions concerning the effects of this incentive scheme in the long run, considering that the lottery was in place only for a limited period of time.

In this connection, the question remains open as to whether the introduction of the lottery could have unexpected effects in a longer time-horizon, such as leading bus riders to substitute monthly or seasonal travel passes with on-board tickets in order to participate in the lottery. For instance, in our analysis, when we considered buses operating in urban and suburban routes separately, we saw that for the latter group the introduction of the incentive scheme targeting on-board tickets determined a significant reduction in off-board sales. Therefore, we have some evidence that, at least for passengers traveling on suburban routes, the incentive scheme determined a substitution effect. And even considering the overall sample, the substitution between on-board and off-board tickets may not have happened during the relatively short period in which our experiment was conducted, but might be a possibility if such lotteries were implemented permanently.

We also cannot rule out the possibility of substitution effects between participating in lotterybased incentive schemes and other gambling activities. For instance, Cookson (2016) showed that, in Nebraska, the introduction of prize-linked saving accounts was associated with a reduc- 
tion of $3 \%$ in casino gambling. Future research should investigate: (i) the persistence and the long-term effects of the lottery-based incentive scheme coupled with probabilistic sanctions, and (ii) whether this incentive scheme reduces the demand for other existing gambling activities.

A limitation of our experimental design is that it does not make it possible to single out the mechanism behind the increase in ticket sales. Our data cannot explain whether potential faredodgers purchased more tickets because of the attraction for gambling or motivated by other reasons. Similarly, we cannot rule out with certainty that passengers perceived the introduction of the incentive scheme as being coupled with an increased monitoring activity by the bus company. However, we have reason to consider this possibility unlikely: the lottery was clearly presented as a promotional campaign by the bus company and in no way were references to enforcement made during the marketing campaign.

\section{Conclusion}

In this paper, we studied an incentive scheme aiming to increase compliance, which couples a probabilistic sanctioning mechanism with lottery-based rewards. To test the performance of this incentive scheme, we set up a field experiment in the context of local public transportation. We organized a lottery in which participation was linked to buying a valid bus ticket on board the bus. We created two samples of treated and control buses; they were identical except that passengers of the former were informed that the incentive scheme was in place, upon entering the bus. We then compared the data on on-board ticket sales (participating in the lottery) in the two samples during the lottery period and in the preceding and following months. We also checked for possible side effects on off-board tickets (not included in the incentive scheme).

During the experimental period, passengers on treated buses purchased significantly more on-board tickets than those on control buses. Overall, off-board sales remained unaffected by the lottery introduction. However, when data were analyzed separately for buses circulating on urban and suburban routes, we found that passengers of the latter purchased less off-board tickets during the lottery period.

In our experiment, the lottery resulted cost-effective and generated positive net profits, but only because not all the prizes were claimed by the winners. Therefore, it remains unclear whether the incentive scheme we studied can be self-financing. Our experimental design was not suited to answering questions regarding the long run effects of the incentive scheme. Future research shall establish whether and to what extent the results achieved in the month in which the lottery was in place can be sustained in the long run. Moreover, additional studies shall clarify whether the participation in the lottery-based incentive scheme reduces participation in other gambling activities. 


\section{References}

Acland, D. and Levy, M. (2010). Habit formation and naivete in gym attendance: evidence from a field experiment. Unpublished paper.

Alm, J., Jackson, B. R., and McKee, M. (1992). Estimating the determinants of taxpayer compliance with experimental data. National Tax Journal, pages 107-114.

Ambrus, A. and Greiner, B. (2012). Imperfect public monitoring with costly punishment: An experimental study. The American Economic Review, 102(7):3317-3332.

Andreoni, J., Harbaugh, W., and Vesterlund, L. (2003). The carrot or the stick: Rewards, punishments, and cooperation. The American Economic Review, 93(3):893.

Angrist, J. and Lavy, V. (2009). The effects of high stakes high school achievement awards: Evidence from a randomized trial. The American Economic Review, 99(4):1384-1414.

Babcock, P. S. and Hartman, J. L. (2010). Networks and workouts: Treatment size and status specific peer effects in a randomized field experiment. Technical report, National Bureau of Economic Research.

Balliet, D., Mulder, L. B., and Van Lange, P. A. (2011). Reward, punishment, and cooperation: a meta-analysis.

Bettinger, E. P. (2012). Paying to learn: The effect of financial incentives on elementary school test scores. Review of Economics and Statistics, 94(3):686-698.

Bjorkman Nyqvist, M., Corno, L., de Walque, D., and Svensson, J. (2015). Using lotteries to incentivize safer sexual behavior: evidence from a randomized controlled trial on hiv prevention.

Bowles, S. and Hwang, S.-H. (2008). Social preferences and public economics: Mechanism design when social preferences depend on incentives. Journal of Public Economics, 92(8):1811-1820.

Brandts, J. and Cooper, D. J. (2006). A change would do you good... an experimental study on how to overcome coordination failure in organizations. The American Economic Review, 96(3):669-693.

Bruttel, L. and Friehe, T. (2014). Can short-term incentives induce long-lasting cooperation? results from a public-goods experiment. Journal of Behavioral and Experimental Economics, 53:120-130.

Cawley, J. and Price, J. A. (2009). Outcomes in a program that offers financial rewards for weight loss. Technical report, National Bureau of Economic Research. 
Charness, G. and Gneezy, U. (2009). Incentives to exercise. Econometrica, 77(3):909-931.

Clotfelter, C. T. and Cook, P. J. (1991). Selling hope: State lotteries in America. Harvard University Press.

Cookson, J. A. (2016). When saving is gambling. Technical report.

Dai, Z., Galeotti, F., and Villeval, M. C. (2017). Cheating in the lab predicts fraud in the field: An experiment in public transportation. Management Science.

Dai, Z., Hogarth, R. M., and Villeval, M. C. (2015). Ambiguity on audits and cooperation in a public goods game. European Economic Review, 74:146-162.

Dwenger, N., Kleven, H., Rasul, I., and Rincke, J. (2016). Extrinsic and intrinsic motivations for tax compliance: Evidence from a field experiment in germany. American Economic Journal: Economic Policy, 8(3):203-232.

Fabbri, M. (2015). Shaping tax norms through lotteries. International Review of Law and Economics, 44(C):8-15.

Fehr, E. and Schmidt, K. M. (2007). Adding a stick to the carrot? the interaction of bonuses and fines. The American Economic Review, 97(2):177-181.

Filiz-Ozbay, E., Guryan, J., Hyndman, K., Kearney, M., and Ozbay, E. Y. (2015). Do lottery payments induce savings behavior? evidence from the lab. Journal of Public Economics, $126: 1-24$.

Fryer Jr, R. G. (2011). Financial incentives and student achievement: Evidence from randomized trials. The Quarterly Journal of Economics, 126(4):1755-1798.

Fürst, E. (2012). Free riders and ticket fraud in public transport: A delphi analysis. In European Transport Conference 2012.

Fuster, A. and Meier, S. (2010). Another hidden cost of incentives: The detrimental effect on norm enforcement. Management Science, 56(1):57-70.

Giles, E. L., Robalino, S., McColl, E., Sniehotta, F. F., and Adams, J. (2014). The effectiveness of financial incentives for health behaviour change: systematic review and meta-analysis. PloS one, $9(3): \mathrm{e} 90347$.

Gneezy, U., Meier, S., and Rey-Biel, P. (2011). When and why incentives (don't) work to modify behavior. The Journal of Economic Perspectives, 25(4):191-209.

Gneezy, U. and Rustichini, A. (2000). A fine is a price. The Journal of Legal Studies, 29(1):1-17. 
Gürerk, Ö., Irlenbusch, B., and Rockenbach, B. (2006). The competitive advantage of sanctioning institutions. Science, 312(5770):108-111.

Haisley, E., Cryder, C., Loewenstein, G., and Volpp, K. (2008). The appeal of lotteries and their use in incentive design. Society for Judgment and Decision Making Preconference: Using Human Nature to Improve Human Life, Chicago, 14.

Hogarth, R. M. and Villeval, M. C. (2014). Ambiguous incentives and the persistence of effort: Experimental evidence. Journal of Economic Behavior \& Organization, 100:1-19.

John, P., MacDonald, E., and Sanders, M. (2015). Targeting voter registration with incentives: A randomized controlled trial of a lottery in a london borough. Electoral Studies, 40:170-175.

Kearney, M. S., Tufano, P., Guryan, J., and Hurst, E. (2010). Making savers winners: An overview of prize-linked savings products. Technical report, National Bureau of Economic Research.

Koelle, F., Lane, T., Nosenzo, D., and Starmer, C. (2017). Nudging the electorate: what works and why? Technical report.

Kraft-Todd, G., Yoeli, E., Bhanot, S., and Rand, D. (2015). Promoting cooperation in the field. Current Opinion in Behavioral Sciences, 3:96-101.

Landry, C. E., Lange, A., List, J. A., Price, M. K., and Rupp, N. G. (2006). Toward an understanding of the economics of charity: Evidence from a field experiment. The Quarterly Journal of Economics, 121(2):747-782.

Lange, A., List, J. A., and Price, M. K. (2007). Using lotteries to finance public goods: Theory and experimental evidence. International Economic Review, 48(3):901-927.

Lefebvre, M., Stenger, A., et al. (2016). Long-lasting effects of temporary incentives in public good games. Technical report, Bureau d'Economie Théorique et Appliquée, UDS, Strasbourg.

Levitt, S. D., List, J. A., and Sadoff, S. (2016). The effect of performance-based incentives on educational achievement: Evidence from a randomized experiment. Technical report, National Bureau of Economic Research.

Mazar, N. and Ariely, D. (2006). Dishonesty in everyday life and its policy implications. Journal of public policy and Marketing, 25(1):117-126.

Mazar, N., Shampanier, K., and Ariely, D. (2016). When retailing and las vegas meet: Probabilistic free price promotions. Management Science.

Mellström, C. and Johannesson, M. (2008). Crowding out in blood donation: was titmuss right? Journal of the European Economic Association, 6(4):845-863. 
Morgan, J. (2000). Financing public goods by means of lotteries. The Review of Economic Studies, 67(4):761-784.

Morgan, J. and Sefton, M. (2000). Funding public goods with lotteries: experimental evidence. The Review of Economic Studies, 67(4):785-810.

Nalbantian, H. R. and Schotter, A. (1997). Productivity under group incentives: An experimental study. The American Economic Review, pages 314-341.

Naritomi, J. (2013). Consumers as tax auditors. Job market paper, Harvard University.

Nosenzo, D., Offerman, T., Sefton, M., and van der Veen, A. (2015). Discretionary sanctions and rewards in the repeated inspection game. Management Science, 62(2):502-517.

Panagopoulos, C. (2012). Extrinsic rewards, intrinsic motivation and voting. The Journal of Politics, 75(1):266-280.

Schultz, T. P. (2004). School subsidies for the poor: evaluating the mexican progresa poverty program. Journal of development Economics, 74(1):199-250.

Sefton, M., Shupp, R., and Walker, J. M. (2007). The effect of rewards and sanctions in provision of public goods. Economic inquiry, 45(4):671-690.

Thaler, R. H. and Ziemba, W. T. (1988). Anomalies: Parimutuel betting markets: Racetracks and lotteries. The Journal of Economic Perspectives, 2(2):161-174.

Torgler, B. (2003). Beyond punishment: a tax compliance experiment with taxpayers in costa rica. Revista de Analisis Economico-Economic Analysis Review, 18(1):27-56.

Volpp, K. G., Loewenstein, G., Troxel, A. B., Doshi, J., Price, M., Laskin, M., and Kimmel, S. E. (2008). A test of financial incentives to improve warfarin adherence. BMC health services research, 8(1):272.

Volpp, K. G., Troxel, A. B., Pauly, M. V., Glick, H. A., Puig, A., Asch, D. A., Galvin, R., Zhu, J., Wan, F., DeGuzman, J., et al. (2009). A randomized, controlled trial of financial incentives for smoking cessation. New England Journal of Medicine, 360(7):699-709. 